\title{
A educação ainda é importante para a mobilidade social? Uma perspetiva das desigualdades educacionais da Europa do sul no contexto europeu
}

\author{
Susana da Cruz Martinsi, Rosário Maurittii, Nuno Nunesiii \\ \& António Firmino Costaiv \\ Instituto Universitário de Lisboa, Portugal
}

Ana Lúcia Romãov

Universidade de Lisboa, Portugal

Resumo

Com a expansão generalizada das qualificações na Europa, algumas abordagens têm vindo a defender que a dimensão educativa se tem enfraquecido enquanto fator implicado na mobilidade social e como elemento estrutural nas desigualdades e oportunidades sociais. Este estudo perspetiva, quer nos seus posicionamentos teóricos quer na sua verificação empírica, as desigualdades educacionais e as suas implicações na mobilidade e nas desigualdades sociais entre países do Sul, e entre este conjunto e a Europa no seu todo. Esta análise é, ainda, contextualizada através do reconhecimento de dinâmicas educacionais dos últimos 60 anos. O seu desenvolvimento visa, também, aprofundar a importância das origens educativas nos destinos educativos e socioprofissionais e identificar padrões de fluidez educativa e de desigualdade educacional, contextualizando-os no quadro de transições educacionais diferenciadas em termos nacionais. $O$ inquérito internacional European Social Survey (2012) é a referência empírica central.

Palavras-chave

Desigualdades educativas; Mobilidade social; Europa do sul; Contexto europeu 


\section{Introdução}

Este artigo aponta para o debate sobre a importância da educação e dos processos de reconfiguração e mobilidade educativa no acesso a oportunidades sociais e recursos nas sociedades contemporâneas. A questão não é trivial, uma vez que alguns autores têm vindo a defender que, na atualidade e por via da expansão escolar, essa importância teria desaparecido devido a processos de desclassificação das credenciais académicas (DuruBellat, 2006, 2007) ou de sobrequalificação dos indivíduos, reduzindo-se drasticamente as possibilidades de acesso a profissões qualificadas e de ocupação de certas posições sociais (Chevalier \& Lindley, 2007; Dolton \& Silles, 2003). No entanto, o estudo aqui desenvolvido, sustentado em informação substantiva, permite confirmar a educação como uma dimensão muito influente na explicação de processos de mobilidade e enquanto elemento estrutural das desigualdades sociais nas sociedades europeias.

As dinâmicas da sociedade do conhecimento no atual contexto de crise colocam uma acrescida relevância teórica nas relações entre educação e mobilidade social (Maurin, 2009; Alves, Baptista, Cantante, \& Carmo, 2011; Costa, 2012). Um conjunto de pesquisas e análises tem vindo a incidir na relevância dos recursos educativos nos mercados de trabalho e nos estilos de vida (Martins, Mauritti, \& Costa, 2007; Mauritti \& Martins, 2014), bem como na importância desses recursos na acentuação ou na diminuição das desigualdades, ou ainda na redução da vulnerabilidade a exclusões sociais (Costa, 2012). Outras análises aprofundam ainda a influência do estado social, dos sistemas educativos e das políticas educativas na mobilidade social, e nas inter-relações entre origens sociais, desigualdades educativas e oportunidades sociais, nos diferentes contextos nacionais e momentos históricos (Breen \& Jonsson, 2007; Meschi \& Scervini, 2012; Oesch, 2015).

Procura-se, neste estudo, abordar estas temáticas, em termos de posicionamentos teóricos e de verificação empírica, tendo por referência o contexto europeu. Visa-se, em particular, a comparação entre o conjunto europeu e um subconjunto de países do sul da Europa (nomeadamente Portugal, Espanha e Itália). Tal perspetiva comparativa será contextualizada através do reconhecimento das grandes dinâmicas educacionais dos últimos 60 anos. 
No sentido de sustentar a nossa posição neste debate, delineámos os seguintes objetivos analíticos: em primeiro lugar, o reconhecimento e a caracterização das dinâmicas e transições-chave no alargamento da escolaridade na Europa, numa perspetiva histórica; em segundo lugar, a identificação de processos de mobilidade educacional e transformações observadas nas estruturas socioeducacionais; e, por fim, a análise da educação como um elemento estrutural na desigualdade e nas oportunidades sociais. Procurou-se aferir, ainda, de que modo a variável género se associa à dimensão educativa na explicação de alguns dos processos de mobilidade identificados. Sabe-se que, em muitos casos, as mulheres têm protagonizado dinâmicas de abertura no acesso a algumas categorias sociais e entrado de forma dominante em dinâmicas de mobilidade educacional.

Do ponto de vista da estratégia metodológica, são utilizadas diferentes fontes empíricas, sendo central a utilização da base de dados do European Social Survey (ESS) de 2012. No quadro desta referência, foram considerados 24 países abrangidos por esta ronda - 21 da União Europeia e três países associados do Espaço Económico Europeu (Islândia, Noruega e Suíça). Os microdados do ESS permitem trabalhar, de forma direta e para o conjunto dos países europeus, indicadores de mobilidade educativa, categorias profissionais e rendimentos. Para uma perspetiva mais contextual e de identificação das principais dinâmicas de escolarização, para além dos dados do ESS, foram também utilizados documentos que tomam por base fontes como o Banco Mundial e a UNESCO (a partir das bases de dados de Robert Barro e Jong-Wha Lee), permitindo comparações e diacronias mais alargadas. Através de uma leitura articulada e conjunta destas várias fontes de informação, pretendemos, pois, contribuir para o debate sobre as desigualdades educacionais e a mobilidade social.

\section{Enquadramento e perspetivas teórico-analíticas}

Com a expansão muito generalizada dos processos educativos e qualificacionais na Europa, têm sido propostas perspetivas que dão conta de um forte enfraquecimento da dimensão educativa enquanto fator implicado na mobilidade social, e como elemento estrutural das desigualdades e oportunidades sociais. Por exemplo, as últimas perspetivas enunciadas por Marie Duru-Bellat $(2006,2007)$ remetem para a desclassificação dos recursos 
educacionais, os quais, segundo a própria, representam um investimento de risco, dado o processo de inflacionamento das credenciais escolares e do número limitado de posições de prestígio e bem remuneradas que o mercado de trabalho pode oferecer. Nessas orientações, a autora tem sido acompanhada por outro sociólogo francês que trabalha de forma muito persistente a educação e as desigualdades sociais, François Dubet (Dubet \& Duru-Bellat, 2000), e em outros trabalhos propondo também comparações internacionais (Dubet, Duru-Bellat, \& Vérétout, 2010, 2012).

Com uma outra abordagem, mas de certa forma em convergência com estes entendimentos, John H. Goldthorpe $(2012,2014)$ sublinha o enfraquecimento da influência das credenciais escolares e do poder das políticas educativas na mobilidade social. Este autor (Goldthorpe, 2012) dá conta da diminuição da relação entre a educação, as experiências de mobilidade ascendente, e os destinos sociais relacionados (um dos eixos mais importantes no triângulo analítico Origens-Educação-Destinos). Para Goldthorpe (2012), tal aspeto só não se verifica para as mulheres, cujo acesso a maiores níveis de escolaridade - segundo o próprio, muito mediado por via da classe social - Ihes permite aumentar as suas possibilidades de disputar, com os homens, lugares de dirigentes e de profissionais técnicos e científicos.

No fundo, embora estes autores evoquem dimensões alternativas para este debate, convergem na análise de desvalorização ou desclassificação das qualificações, reforçando, por sua vez, a importância das origens sociais como maior determinante nos destinos e oportunidades sociais dos indivíduos.

Tais abordagens advogam em simultâneo que, particularmente com a intensificação da crise financeira internacional, e o incremento de experiências sociais de desemprego, precariedade laboral e subemprego, a educação deixou em boa medida de ser um traço diferenciador, de proteção relativa face a tais situações. Nestas visões, o atual contexto social e económico, também marcado pela redução da capacidade das prestações e funções do estado social, tem permeado quase de forma indistinta a população, mais ou menos qualificada, votando-a a situações de desigualdade e exclusão social, não constituindo pois a educação uma dimensão especialmente relevante na diferenciação dessas condições sociais. 
Nesta discussão tem cabimento, como interpelação analítica, a comparação entre os diferentes sistemas educativos e a influência da educação na mobilidade social e nas condições de vida, no quadro de modelos e formas de atuação dos Estados nacionais. Segundo EspingAndersen (1990), só um trabalho de pesquisa comparada permite desocultar o que une e divide os Estados sociais. Sendo reconhecidas como válidas algumas das críticas à tipologia de classificação dos diversos Estados sociais, a sua complexificação tem permitido a identificação de outros tipos de Estadoprovidência, nomeadamente e especialmente relevante para este artigo, a configuração da Europa do sul (Silva, 2009; Ferrera, 2005). Estas propostas são de grande utilidade na compreensão da relação dos Estados do sul da Europa, com as transformações sociais e os mercados de trabalho contemporâneos - não obstante a controvérsia recente em torno da existência, ou não, de um modelo consistente de Estado social do Sul (como discutem Capucha, Estêvão, Calado, \& Capucha, 2014).

Ora, a educação apresenta-se como um dos setores nucleares de atuação do Estado. No que toca a esta área e, mais concretamente, aos sistemas educativos, evidencia-se, pelo menos, uma capacidade e desempenhos próprios, que tornam a Europa do sul uma configuração de défice qualificacional, embora com uma relativa recuperação no contexto europeu (Martins, 2012). Tais modos de relação conferem assim à educação um elemento decisivo nas condições e oportunidades de vida, particularmente no contexto dos países do sul da Europa.

A partir da análise de estudos já realizados e dos dados empíricos, o presente trabalho procura, pois, sublinhar a educação como uma dimensão muito influente nos processos estruturais de configuração de sistemas de oportunidades e constrangimentos. Um conjunto de autores com trabalhos importantes, relativamente recentes, tem estado no centro desta problemática, posicionando precisamente a educação na análise dos processos de mobilidade e das desigualdades sociais, e enfatizando a comparação entre países europeus: veja-se, entre outros, Herman van Werfhorst (2007); ou Richard Breen, nomeadamente com Jan O. Jonsson (Breen \& Jonsson, 2005); ou com os contributos de uma equipa mais alargada, como Richard Breen, Ruud Luijkx, Walter Müller, e Reinhard Pollak (2009, 2010), que reequacionam estas desigualdades à luz da desigualdade educativa entre géneros. 
Autores como Breen e Jonsson (2005) focam-se na ligação entre as origens sociais e os destinos na estrutura ocupacional, documentando empiricamente como a validade analítica destas relações no tempo tem sido importante, embora muito subsidiárias dos contextos nacionais e das suas dinâmicas específicas, nomeadamente no que respeita ao peso das origens educacionais. Estes autores (Breen \& Jonsson, 2007) destacam a maior fluidez na mobilidade social sueca por via do declínio das desigualdades educacionais e uma estrutura educativa mais qualificada. Neste contexto, uma maior equidade de rendimentos e das condições de participação no emprego, nomeadamente nos segmentos que têm revelado maiores exigências do ponto de vista da qualificação, parecem estar mais relacionadas com os recursos educativos do que com as origens familiares.

Nesta medida, o argumento de Werfhorst (2007), longe de considerar linear o contributo da educação nesses mecanismos, remete para os efeitos contraditórios registados ao longo do século XX. O autor ressalva, no entanto, que, desde os anos 80, a educação parece ter um impacto mais importante para a obtenção de maiores rendimentos, mesmo que esse contributo não se revele tão claro para o posicionamento numa classe social mais elevada.

Numa grande coincidência de objeto de estudo e usando o mesmo inquérito europeu de referência do nosso estudo (embora com anos diferentes), veja-se Elena Meschi e Francesco Scervini (2012), que denotam que as desigualdades educacionais surgem com maior visibilidade nas fases iniciais do processo de expansão escolar; e a equipa de Majka van Doorn, loana Pop, e Maarten H. J. Wolbers (2011), que estabelece um diálogo, precisamente, com as propostas de Breen e Jonsson (2005), evidenciando as características contextuais de diferentes países e a identificação de segmentos que desempenham um papel fundamental na determinação da transmissão intergeracional da educação. Estes autores procuram analisar como é que estas características contextuais interagem com as origens familiares e a formação de padrões de mobilidade educativa intergeracional em diferentes contextos societais e momentos históricos, tendo em consideração dimensões como o grau de industrialização, a participação da mulher no mercado de trabalho, a estrutura do sistema educativo e o regime político do país. 


\section{A escolarização da população europeia}

O fim da II Guerra Mundial marca o início de uma nova era para a Europa, consubstanciada, no plano educativo, em maiores investimentos nos sistemas educativos, no acesso generalizado à escola por parte de todas as classes sociais e em renovadas oportunidades de mobilidade social. Mas as realidades políticas são diversas no contexto europeu, revelando-se mais ou menos abertas a processos alargados de escolarização no interior dos respetivos países europeus (Therborn, 1995).

A figura 1 evidencia o alargamento diferenciado das dinâmicas de acesso à educação na Europa, permitindo um primeiro enquadramento histórico sobre o desempenho dos sistemas educativos e respetiva capacidade de escolarizar as suas populações ao longo dos últimos 60 anos. Nesta figura, assinalam-se três momentos - 1950, 1980 e 2010 - e os países estão alinhados segundo o número médio de anos completos de escolaridade em 2010, numa população com 25 e mais anos.

Iniciando a nossa análise no momento mais recuado da figura, 1950, dá-se conta de um diferencial abissal entre os vários países europeus. Alguns destes, cuja forte marca educativa nas suas populações é já muito evidente nesse ano, dizem respeito a contextos nacionais que viram na educação uma dimensão importante e constituinte de um plano de recuperação do pós-II Guerra Mundial, e de aceleração do crescimento económico. É também interessante apurar o sentido político antecipado, entre estes países, de aplicação efetiva de uma escolaridade obrigatória (Martins, 2012). As posições com mais anos completos de escolaridade são sobretudo ocupadas por países da Europa Central, alguns de Leste, e do Norte (Suíça, Eslováquia, República Checa, Noruega e Hungria).

No extremo oposto, onde Portugal se situa, identificamos contextos de um enorme défice educacional, expressão de uma boa parte das populações nacionais que, em meados do século passado, não chegaram sequer aos bancos da escola. A posição relativa de Portugal, em destaque neste segmento, denota um parco apoio político a uma escolarização efetiva, com uma política em relação à escolaridade obrigatória muito titubeante e até de redução, em alguns dos períodos do Estado Novo (Martins, 2010; Almeida \& Vieira, 2006). 


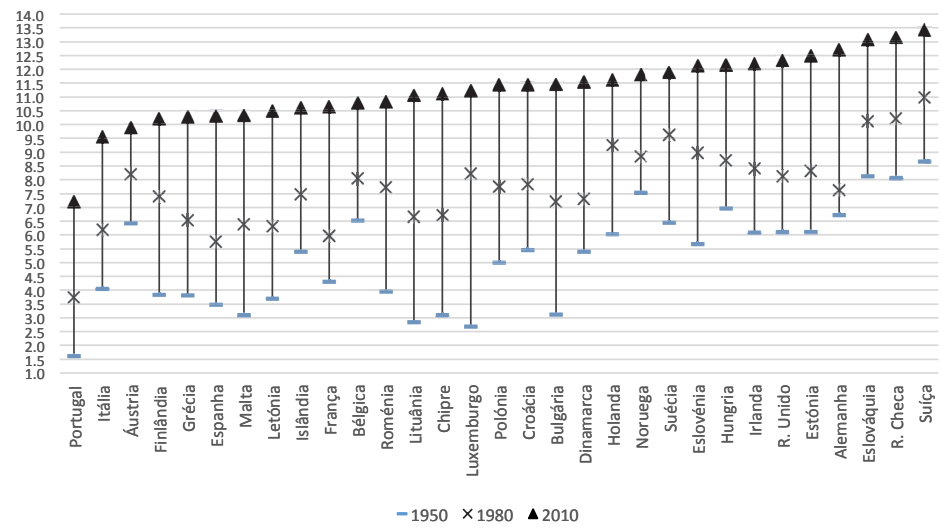

(Fontes: World Bank - a partir dos dados e metodologia de Robert Barro \& Jong-Wha Lee, em www.barrolee.com - e Unesco Dataset; consultadas em maio de 2015)

Figura 1 - Escolarização na Europa, população $\geq 25$ anos, 1950-19802010 (média de anos de escolaridade)

Quanto à cadência do aumento da escolarização, existem também informações muito relevantes na figura 1: é possível observar que aquela tende a ser mais intensa sobretudo a partir de 1980, nomeadamente nos países que demoraram a implementar regimes democráticos, sobretudo no sul da Europa, como Portugal e Espanha. Nestes dois países da Península Ibérica, como noutros contextos europeus, a democracia passa a ser um tipo de regime promotor de dinâmicas de alargamento e de maior inclusão por parte dos sistemas educativos (Martins, Nunes, Mauritti, \& Costa, 2014).

Em 2010, verifica-se uma relativa convergência nos processos de escolarização dos europeus, apontando-se 11 a 12 anos como referência média dos anos de escolaridade. Apesar do sentido de forte confluência verificado até 2010, Portugal ainda se encontra numa posição muito distante dos outros países europeus.

A expressão das diferenças nacionais e os momentos históricos de maior abertura dos sistemas educativos europeus devem alertar-nos para a sua relação com as desigualdades e processos de mobilidade social e 
educativa (Breen \& Jonsson, 2005; Haim, Shavit, \& Ayalon, 2007; van Doorn, Pop, \& Wolbers, 2011; Meschi \& Scervini, 2012).

\section{O alargamento das escolaridades e a mobilidade educativa}

Os processos de escolarização da população europeia implicaram o alargamento das escolaridades e, geracionalmente, a reprodução ou o incremento da mobilidade educativa, consoante os pontos de partida nos contextos nacionais, o nível de escolarização das diferentes gerações (de progenitores e filhos) e as condições de desempenho dos sistemas educativos.

A figura 2 evidencia os processos de mobilidade educativa de indivíduos com 25 a 64 anos. Esta figura põe em evidência a relação entre a escolaridade dos pais, construída segundo um critério de dominância (tendo em conta o nível de escolaridade mais elevado do pai ou da mãe), e dos filhos. A diferença é medida em níveis da Classificação Internacional Tipo de Educação (CITE) ${ }^{1}$ - aqui apresentados nos seis níveis da tipologia de educação da UNESCO, de 1997, tal como são descritos no indicador dos níveis de escolaridade no ESS (2012). Nesta análise utilizámos dados do ESS, nomeadamente pela necessidade de usar microdados que nos permitissem construir e cruzar este tipo de indicadores. A figura alinha os países em função da mobilidade educacional ascendente (ou seja os filhos, neste caso os inquiridos, terem melhores níveis CITE face aos pais).

Considerando os dados em referência (figura 2), uma primeira observação é sugerida: em metade dos 24 países analisados, mais de $50 \%$ dos inquiridos ascendeu no quadro de uma mobilidade educativa. Os países onde a reconfiguração dos perfis de escolarização foi mais intensa, envolvendo pelo menos dois níveis da CITE, são: Chipre, Espanha, França, Irlanda, Finlândia, Suécia, Reino Unido e Dinamarca. Este segmento inclui países de várias zonas europeias, em alguns casos permitindo reforçar um forte protagonismo neste processo (como é o caso da Suécia e da Dinamarca), noutros tornando bem visível o "salto" qualitativo nas últimas décadas (como é o caso da Finlândia e do Reino Unido), graças a reformas políticas muito atuantes e investimentos intensificados (Martins, 2012). 
Depois, seguem-se países com uma lógica de recuperação (visível sobretudo em Espanha e na Irlanda).

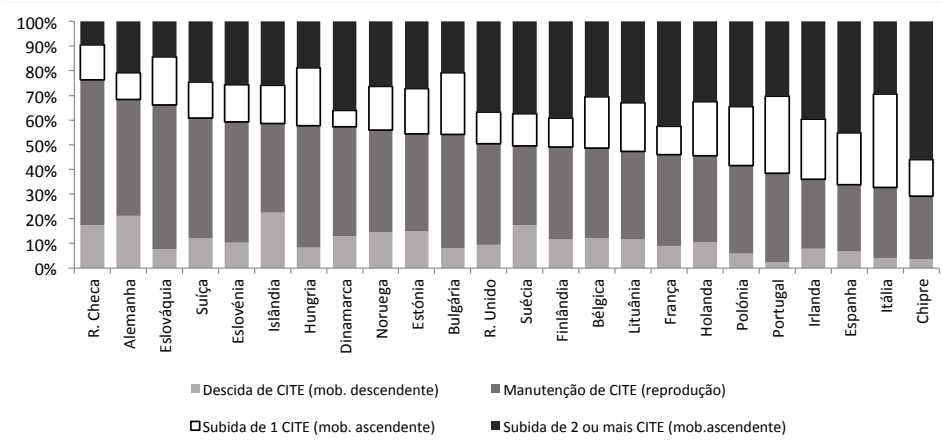

Nota: Na operacionalização do indicador do nível de escolaridade dos pais optou-se por atribuir ao agregado doméstico a escolaridade do progenitor com maior nível de escolaridade.

(Fonte: European Social Survey, 2012)

Figura 2 - Mobilidade educativa na Europa, 25-64 anos, 2012 (\%)

A análise conjugada entre as figuras 1 e 2 permite verificar que, em termos gerais, os países que anteciparam de forma mais forte a escolarização das respetivas populações tendem a ter uma mobilidade educativa mais moderada (como a República Checa, a Eslováquia ou a Suíça). Pelo contrário, os países que tardaram nestes processos tendem a apresentar atualmente um maior vigor ascendente. Se considerarmos a mobilidade mais intensa (dois níveis CITE ou mais), podemos observar países como o Chipre, a Espanha, a França ou a Irlanda. Contudo, não nos foi possível identificar os países do Sul como promotores dessa mobilidade educativa, apesar de se reunirem aí os países mais deficitários da Europa em termos de recursos educativos (Martins, 2012). Em Portugal, apesar de se ter verificado uma melhoria dos perfis de escolaridade dos indivíduos em idade ativa, a mesma envolve sobretudo um nível da CITE. Tal dá conta da dificuldade das políticas educativas, numa intervenção direta e consistente no tempo, na estrutura socioeducativa portuguesa. 
Por outro lado, este aspeto não pode ter um entendimento linear; vejase a Dinamarca, a Suécia e o Reino Unido, cuja mobilidade ascendente tem um carácter muito reforçado na percentagem dos que sobem pelo menos dois níveis CITE. Parte destes países tiveram nas últimas décadas políticas educativas de promoção da equidade nos seus sistemas, como a gratuitidade de serviços e recursos educativos e apoios em matéria da ação social, fazendo diminuir o peso das origens sociais nas oportunidades educativas (cf. Breen \& Jonsson, 2007).

Mas o certo é que os processos de mobilidade educativa têm sido sentidos de forma muito evidente, sobretudo nas últimas gerações, sendo excecional para todos os países a manifestação de movimentos descendentes.

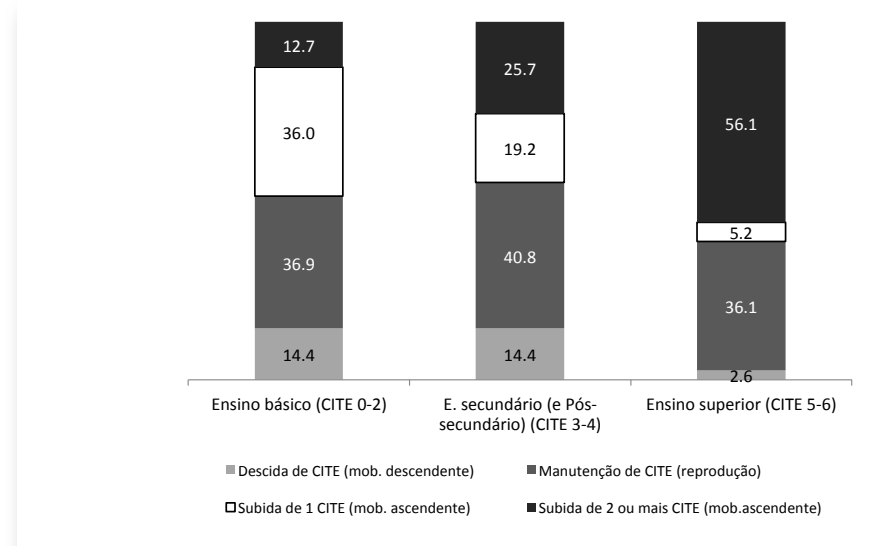

(Fonte: European Social Survey, 2012)

Figura 3 - Mobilidade educativa por nível de escolaridade, na Europa, 25-64 anos, $2012(\%)$

As figuras 3 e 4 servem de base à leitura dos processos de mobilidade educacional relativos ao conjunto de indivíduos de determinado nível de escolaridade, tendo por referência o todo europeu e os países do Sul.

$\mathrm{Na}$ Europa é bastante significativo o peso dos indivíduos que reproduzem o nível de escolaridade dos pais. Entre os respondentes ao ESS 
que detêm um diploma do ensino superior, 36\% têm pais com o mesmo perfil de escolarização, num processo manifesto de reprodução social. Tal evidencia um alargamento do ensino superior que se iniciou, precisamente, com os pais diplomados dos que hoje estão em idade ativa. No entanto, os processos de requalificação por via de uma forte mobilidade educativa não se têm vindo a enfraquecer - aspeto evidente no peso muito importante daqueles que protagonizam trajetórias ascendentes relativamente intensas, a melhorarem em pelo menos dois níveis da CITE (56\%), sendo apenas 5\% aqueles que avançam um nível da CITE.

Estas tendências de reconfiguração dos perfis de escolarização, especificamente no segmento dos que completaram o ensino superior, são muito acentuadas no conjunto europeu, mas especialmente expressivas nos países do Sul, e sobretudo em Portugal, país que, como pudemos ver atrás, está ainda longe de ter atingido um limiar de qualificação equivalente aos padrões europeus (aspeto já verificado em Martins, 2012; e Costa, Mauritti, Martins, Nunes, \& Romão, 2015). Mais de $80 \%$ dos inquiridos portugueses com ensino superior melhora face à família de origem dois níveis ou mais da CITE, revelando um progresso extraordinário, e que só se vai sentindo de forma diferida no tempo. Tanto em Espanha como em Itália essas experiências são também muito significativas, envolvendo mais de dois terços das suas amostras.

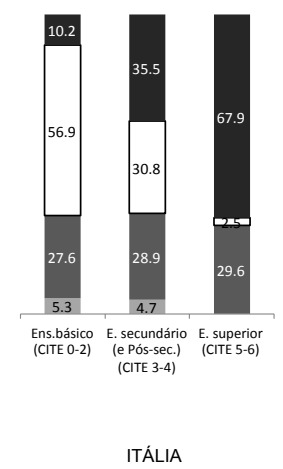

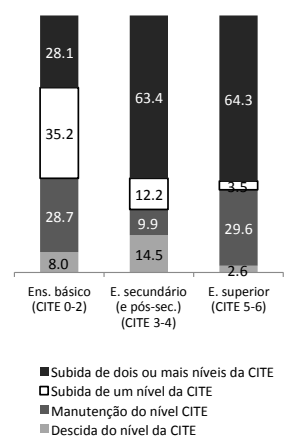

ESPANHA

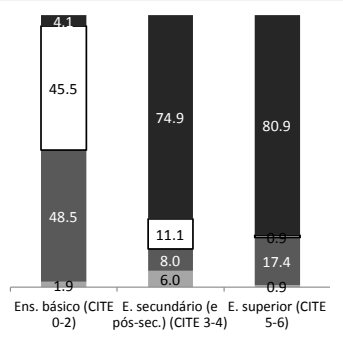

PORTUGAL

(Fonte: European Social Survey, 2012)

Figura 4 - Mobilidade educativa por nível de escolaridade, na Europa do sul, 25-64 anos, 2012 (\%) 
$\mathrm{Na}$ figura 4, Portugal destaca-se também no segmento de respondentes que não foi além do ensino básico; quase 50\% são provenientes de famílias com o mesmo perfil de escolarização. Tal dá conta de uma relativa inércia do sistema escolar português na recuperação do atraso estrutural no contexto do espaço europeu (já verificado enquanto padrão educativo em Martins, 2012). Esta percentagem é bastante superior à que se verifica em Espanha e Itália, e relativamente importante em relação à média europeia (12 pontos percentuais de diferença).

\section{A educação, as desigualdades e as oportunidades sociais}

A crescente incorporação das qualificações nas várias profissões, ao longo do tempo, constitui uma das mais salientes características das sociedades do conhecimento. As reconfigurações das estruturas ocupacionais caminham a par dos processos de escolarização, variando o acesso a determinados lugares profissionais, principalmente em função dos recursos educativos detidos pelos indivíduos, mas com a necessidade de se tomar em consideração os diferentes contextos nacionais. É igualmente possível relacionar, no conjunto dos países europeus, os recursos económicos (rendimentos) com os recursos educativos (escolaridade).

A figura 5 apresenta informação relativa aos pais (pai e mãe) dos respondentes ao ESS e coloca em sobreposição dois indicadores fundamentais nesta análise: profissões e respetivos perfis de qualificação. Uma primeira leitura destes dados pretende aferir quais eram as qualificações necessárias para se ter acesso a um determinado conjunto de profissões na geração anterior à que hoje está em idade ativa (tomando-se como referência empírica principal os inquiridos do ESS).

Tanto os pais como as mães com o ensino básico concentram-se fortemente nos grupos profissionais com baixas qualificações.

Na distribuição masculina, há uma parte ainda expressiva com baixos perfis de escolarização que exerce profissões de direção e administração pública e empresarial (19\%) e nos grupos de profissões de especialistas, técnicos e chefias intermédias (de quase 9\%). Quanto à distribuição feminina deste segmento com baixa escolarização, distingue-se por reforçar a presença na categoria dos trabalhadores especializados e semiqualificados 
(mais de 70\%). Na comparação com o sexo masculino, as mães marcam uma presença diminuta nas profissões melhor posicionadas da estrutura social (as duas primeiras categorias na figura 5). Nas gerações dos pais dos inquiridos do ESS, as desigualdades de género sobrepõem-se, assim, no sistema de oportunidades de acesso a lugares mais abertos ao setor masculino.
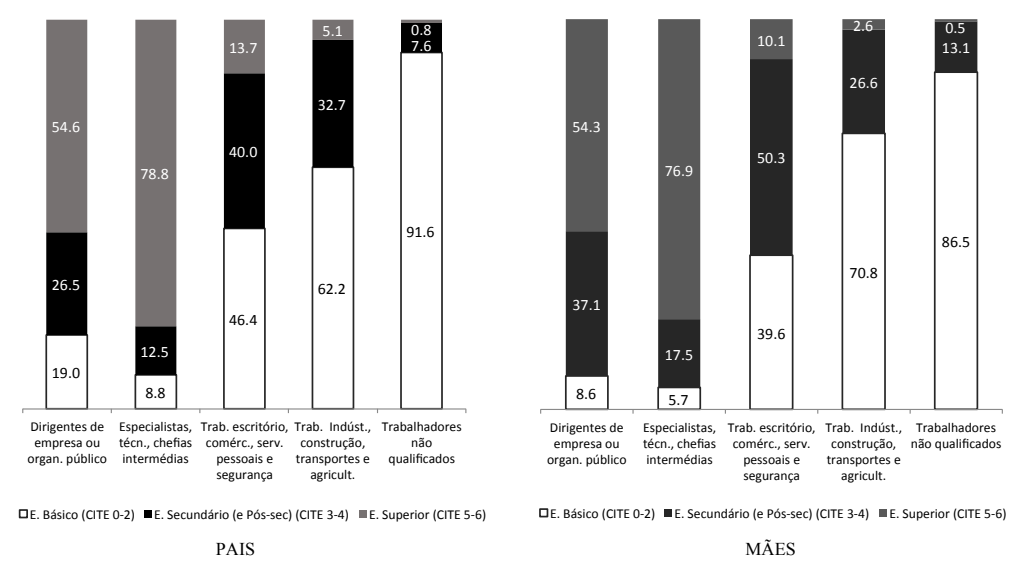

(Fonte: European Social Survey, 2012)

Figura 5 - Nível de escolaridade dos pais por profissão, na Europa, 2012 (\%)

Pais e mães com escolaridade de nível secundário marcam alguma presença em todos os grupos profissionais, mas incidem nos grupos de profissões de base dos serviços administrativos e comerciais, característicos de sociedades de pendor mais urbano e fortemente servicializadas.

A distribuição dos progenitores com perfil de escolarização superior é particularmente incidente no grupo dos profissionais e especialistas qualificados e nas profissões de direção e administração. Tal indica que o recrutamento para estes grupos profissionais tinha como condição preferencial - e veremos que ainda tem - este tipo de diploma. 
A figura 6 dá conta das qualificações da atual estrutura profissional da Europa, nos indivíduos de 25 a 64 anos. Estes dados proporcionam uma observação muito elucidativa: a replicação dessa estrutura para homens e mulheres, face à dos pais, pelo menos nas suas distribuições principais. Embora, como seria de esperar, se tivesse registado algum aumento da escolarização em determinados grupos profissionais, esta, por si só, é uma verificação de grande valor para o debate central neste trabalho.

O espaço de inclusão profissional dos trabalhadores que não detêm o nível secundário tende a diminuir. Este aspeto é uma das expressões mais significativas da transformação das relações entre as estruturas socioeducacional e socioprofissional: o da exigência da obtenção do ensino secundário, como limiar mínimo de acesso e participação no mercado de trabalho, mesmo que tal aconteça nos segmentos de profissionalização reconhecidos como pouco qualificados ou de qualificação intermédia. Embora os que não detêm tal certificação continuem a prevalecer no grupo de profissões não qualificadas e semiqualificadas da indústria e da agricultura, atenuam o seu peso face à estrutura anterior, em ambos os sexos, de forma mais reforçada nas mulheres (como se verifica também em Abrantes \& Abrantes, 2014).

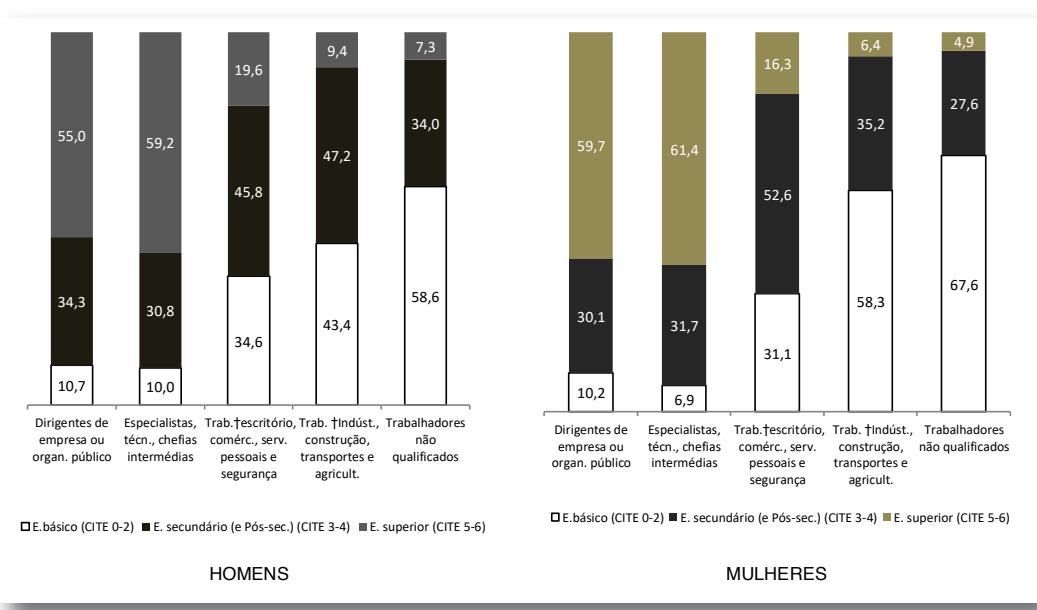

Figura 6 - Nível de escolaridade por profissão, segundo o género, na Europa, 25-64 anos, 2012 (\%) 
O ensino secundário, enquanto nível de escolaridade, marca presença expressiva em todos os segmentos de profissões, mais acentuada nas atividades de base, mas também com significado nas funções mais qualificadas de direção e de especialização técnica.

Os diplomados ao nível do ensino superior, embora ainda com presença mais concentrada nos grupos de profissões qualificados e de claro reconhecimento da sua pericialidade científica e técnica de alto nível, têm também algum peso, mesmo que minoritário, nos restantes segmentos.

Esta análise realça que, além de se ter verificado uma requalificação escolar nas profissões menos qualificadas, o acesso a lugares profissionais de qualificação superior requer, cada vez mais, a posse de níveis elevados de escolaridade. Nesta leitura, não se interpretam tais dinâmicas como uma desvalorização das credenciais escolares, que muitos atribuem à sua generalização (veja-se Duru-Bellat, 2006), mas sim como um requisito essencial e indispensável para $\circ$ acesso a determinadas categorias profissionais, sendo o reverso - a não detenção, por parte dos indivíduos, de recursos qualificacionais - um fator acrescido de risco de exclusão social.

$\mathrm{Na}$ Europa, o padrão de qualificação dos grupos profissionais dos dirigentes e administradores e dos profissionais qualificados e técnicos especialistas é muito equivalente, sendo uma grande maioria (cerca de $60 \%$ ) preenchida por profissionais com o ensino superior, um terço com o ensino secundário e cerca de 10\% com o ensino básico. Tal estrutura de qualificações inverte-se sobretudo na categoria dos trabalhadores não qualificados, mas também na dos trabalhadores qualificados e semiqualificados da indústria, construção, transportes e agricultura (figura 7).

Em Portugal, uma forte maioria dos trabalhadores destas duas últimas categorias (cerca de 90\%) possui apenas escolaridades dos níveis 1 e 2 da CITE (até ensino básico). Não se pode deixar de assinalar que, neste país, a percentagem dos menos escolarizados nos dois primeiros grupos melhor posicionados da estrutura socioprofissional quase dobra face à Europa (figura 8). Parte desta persistência do défice qualificacional português prende-se com a abrangência do grupo etário em análise (privilegiando a população em idade ativa) e a demora, no contexto europeu, da recomposição educativa realizada por via da dinâmica geracional (como se constata, em simultâneo, nas figuras 1 e 2), bem como com as caraterísticas do mercado de trabalho português em 
algumas áreas de atividade económica com resistências conhecidas na incorporação de processos de qualificação e inovação.

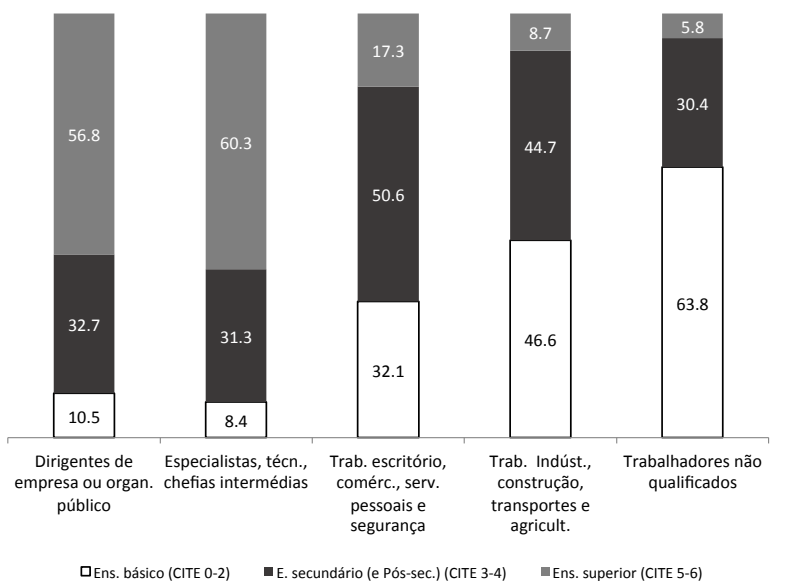

(Fonte: European Social Survey, 2012)

Figura 7 - Nível de escolaridade por profissão, na Europa, 25-64 anos, $2012(\%)$

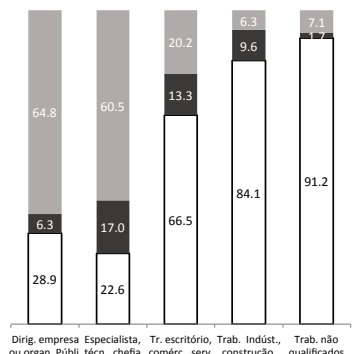

Dirig. empresa Especialista, Tr. escritório, Trab. Indúst., Trab. não
ou organ. Públi. técn., chefia comérc., serv. construçăo, qualificados pessoaise transportes
segurança

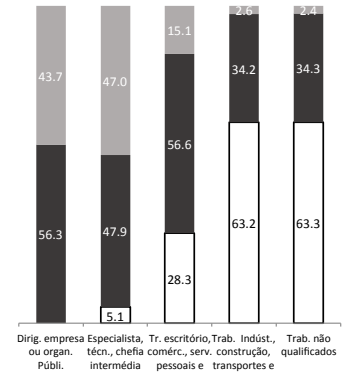

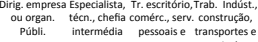

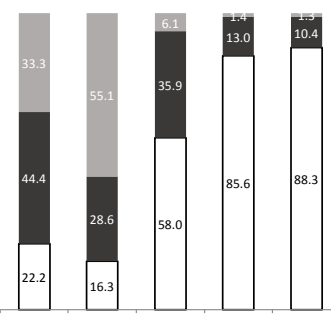

Dirig. empresa Especialista, Tr. escritório, Trab. Indúst., Trab. năo
ou organ. técn., chefía comérc, serv. construçăao, qualificado Públi. intermédia pessoais e transportes

=E. superior (CITE 5-6)

- E. secundário (e Pós-sec.) (CITE 3-4)

DE.básico (CITE 0-2)

ESPANHA

ITÁLIA

PORTUGAL

(Fonte: European Social Survey, 2012)

Figura 8 - Nível de escolaridade por profissão, na Europa do sul, 25-64 anos, 2012 (\%) 
Espanha segue um perfil de qualificações muito equivalente ao de Portugal, sobretudo para os vários grupos profissionais menos qualificados. A distância entre estes dois países é mais evidente nos grupos de dirigentes e de profissionais e técnicos qualificados, existindo uma maior polarização qualificacional em Espanha, onde estas categorias incluem mais diplomados do ensino superior e, em simultâneo, uma maior percentagem de ensino básico.

Em Itália, o ensino secundário tem maior importância nas várias categorias profissionais, competindo diretamente quer com o perfil de escolaridade superior nas profissões melhor qualificadas, quer com os perfis de nível básico nos restantes segmentos.

Tais diferenças dão conta das orientações dos sistemas educativos nestes dois países (Espanha e Itália) e dos seus efeitos nas dinâmicas de participação no mercado de trabalho. Espanha, apesar dos défices qualificacionais, garantiu no contexto europeu uma elevada certificação ao nível da educação terciária. Tal tendência marca, com certeza, a requalificação das estruturas profissionais, tornando subsumida a categoria do ensino secundário, nomeadamente como certificação para entrada em profissões de direção e de enquadramento qualificado. Por outro lado, a certificação ao nível do ensino secundário é bem notada na realidade italiana, dado o investimento na formação de técnicos com esta qualificação, tendo deixado marcas evidentes na sua estrutura profissional - aspeto ainda mais realçado em períodos de maior expansão escolar.

Neste seguimento, a relação da educação com um dos recursos fundamentais nas condições de vida, os rendimentos, é também muito elucidativa da sua importância nas sociedades e economias europeias.

Uma primeira leitura da figura 9 permite-nos identificar, em todos os países europeus, uma relação direta entre a escolaridade e os rendimentos auferidos - quanto mais escolarizados os indivíduos, mais altos são, em termos médios, os seus rendimentos. Em todos os países europeus, sem exceção, os indivíduos com escolaridade superior auferem rendimentos mais elevados do que os indivíduos com o ensino secundário e básico; e os rendimentos dos indivíduos com o ensino secundário são sempre mais elevados do que os rendimentos dos indivíduos com o ensino básico. Tais regularidades são transversais a todo o contexto europeu. 


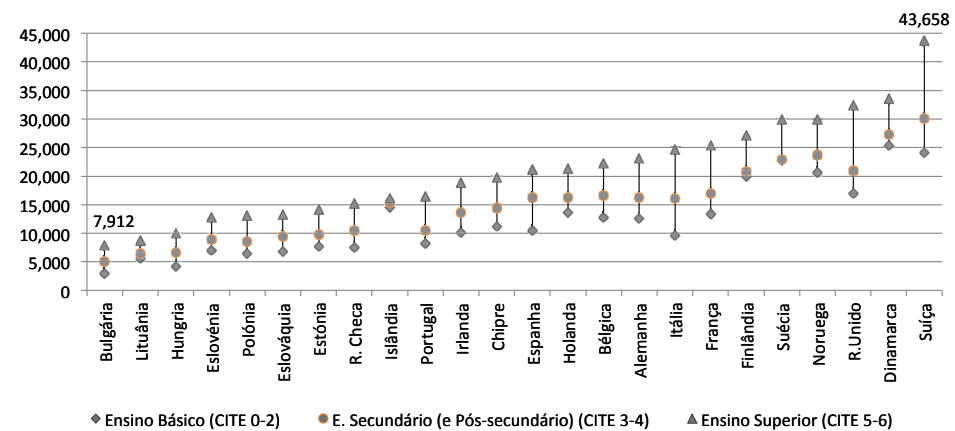

(Fonte: European Social Survey, 2012)

Figura 9 - Rendimentos por nível de escolaridade, na Europa, 25-64 anos, 2012 (rendimento líquido equivalente em PPS, valores médios)

Se se considerar a Europa como um todo, constata-se que são bastante acentuadas as desigualdades de rendimentos entre os países europeus, sendo variável a amplitude dessas desigualdades no interior de cada país, em função dos níveis de escolaridade dos indivíduos. Nos países onde os rendimentos são, em termos médios, muito mais baixos, as diferenças não são tão vincadas - verificando-se uma espécie de nivelamento por baixo.

Em Portugal, a segmentação de rendimentos por via da escolaridade é particularmente notória, com mais uma agravante: como se trata de um dos países menos escolarizados da Europa, só uma pequena parte da população vê melhorados os seus rendimentos por essa via.

\section{Conclusões}

Nos últimos 60 anos, temos observado mudanças significativas na estrutura educacional dos países europeus. Tais transformações põem em evidência processos de forte mobilidade educativa que têm ocorrido até aos dias de hoje. A sua intensidade é muito subsidiária de um conjunto de estruturas e dinâmicas: 
- da generalização da educação, nos seus vários níveis, nomeadamente nos níveis mais altos dos percursos escolares, e em cada país;

- dos contextos nacionais e dos momentos históricos de expansão, bem como das transições educativas relevantes - com traços específicos para o sul da Europa, sublinhando um atraso histórico evidente, mas também processos de recuperação (mais ou menos intensos e mais ou menos continuados, consoante os países);

- de como a distribuição está relacionada com outros tipos de desigualdade, nomeadamente de género.

Neste sentido, as análises anteriores permitem sustentar substantivamente que a dimensão educativa tem efeitos importantes na mobilidade social, nas inserções profissionais e na distribuição dos recursos. Escolaridades mais elevadas conduzem a maiores oportunidades médias de acesso a profissões mais qualificadas e a rendimentos também mais elevados. Essa é uma tónica visível em todos os países europeus. A possibilidade de conseguir qualificações médias ou superiores está longe de ser generalizada, designadamente em países marcados por estruturas sociais muito inigualitárias e por fortes atrasos educativos, como é o caso de Portugal. No entanto, isso não significa que a educação não seja relevante, nomeadamente para os indivíduos provenientes de meios sociais desfavorecidos. Pelo contrário, o empoderamento social que a educação proporciona e as oportunidades de mobilidade social ascendente que ela abre sugerem vivamente a importância de políticas continuadas de alargamento da escolaridade, proporcionando oportunidades de qualificação média e superior à generalidade da população.

\section{Nota}

1 Em inglês: ISCED

\section{Referências}

Abrantes, P., \& Abrantes, M. (2014). Gendering social mobility: A comparative perspective on the nexus of education and class across Europe. Gender and Education, 26(4), 377-396. 
Almeida, A. N., \& Vieira, M. M. (2006). A escola em Portugal: Novos olhares, outros cenários. Lisboa: Ed. ICS.

Alves, N. A., Baptista, I., Cantante, F., \& Carmo, R. (2011). Jovens em transições precárias: Trabalho, quotidiano e futuro. Lisboa: Mundos Sociais.

Breen, R., \& Jonsson, J. O. (2005). Inequality of opportunity in comparative perspective: Recent research on educational attainment and social mobility. Annual Review of Sociology, 31, 223-243.

Breen, R., \& Jonsson, J. O. (2007). Explaining change in social fluidity: Educational equalization and educational expansion in twentieth-century Sweden. American Journal of Sociology, 112(6), 1775-1810.

Breen, R., Luijkx, R., Müller, W., \& Pollak, R. (2009). Non-persistent inequality in educational attainment: Evidence from eight European countries. American Journal of Sociology, 114(5), 1475-1521.

Breen, R., Luijkx, R., Müller, W., \& Pollak, R. (2010). Long-term trends in educational inequality in Europe: Class inequalities and gender differences. European Sociological Review, 26(1), 1-18.

Capucha, L., Estêvão, P., Calado, A., \& Capucha, A. R. (2014). The role of stereotyping in public legitimation: The case of the PIGS label. Comparative Sociology, 13(4), 482-502.

Chevalier, A., \& Lindley, J. (2007). Over-education and skills of UK graduates. CEE DP 79.

Costa, A. F. (2012). Desigualdades sociais contemporâneas. Lisboa: Mundos Sociais.

Costa, A. F., Mauritti, R., Martins, S. C., Nunes, N., \& Romão, A. L. (2015). A constituição de um espaço europeu de desigualdades. Observatório das Desigualdades eWorking Paper, 1/2015, 1-21.

Dolton, P. J., \& Silles, M. (2003). The determination and consequences of graduate overeducation. In F. Büchel, A. de Grip, \& A. Mertens (Eds.), Overeducation in Europe - Current issues in theory and policy (pp. 189-216). Amsterdam: Edward Elgar.

Dubet, F., Duru-Bellat, M., \& Vérétout, A. (2010). Les sociétés et leur école. Emprise du diplôme et cohésion sociale. Paris: Le Seuil.

Dubet, F., Duru-Bellat, M., \& Vérétout, A. (2012). As desigualdades escolares antes e depois da escola: Organização escolar e influência dos diplomas. Sociologias, 14(29), 22-70.

Dubet, F., \& Duru-Bellat, M. (2000). L'hypocrisie scolaire: Pour un collège enfin démocratique. Paris: Ed. Seul.

Duru-Bellat, M. (2006). L'inflation scolaire. Les désillusions de la méritocratie. Paris: Ed. du Seuil.

Duru-Bellat, M. (2007). Social inequality in French education extent and complexity of the issues. In R. Teese, S. Lamb, \& M. Duru-Bellat (Eds.), International studies in educational inequality - Theory and policy (vol. 1, pp. 337-356). Dordrecht/Netherlands: Springer.

Esping-Andersen, G. (1990). The three worlds of welfare capitalism. Princeton: Princeton University Press. 
Ferrera, M. (2005). Welfare states and social safety nets in Southern Europe. In M. Ferrera (Org.), Welfare state reform in Southern Europe: Fighting poverty and social exclusion in Italy, Spain, Portugal and Greece (pp. 1-32). Oxon: Routledge.

Goldthorpe, J. H. (2012). Understanding - and misunderstanding - social mobility in Britain: The entry of the economists, the confusion of politicians and the limits of educational policy. Barnett Papers in Social Research, 2/2012.

Goldthorpe, J. H. (2014). The role of education in intergenerational social mobility: Problems from empirical research in sociology and some theoretical pointers from economics. Rationality and Society, 26, 265-289.

Haim, E. B., Shavit, Y., \& Ayalon, H. (2007). Expansion and inequality of educational opportunity: A comparative multi-level analysis. Tel Aviv University, presentation at the Montreal Meeting of RC28, August, 14-17.

Martins, S. C. (2010). Educar (n)a Europa: Contextos, recursos e percursos de escolarização (Tese de Doutoramento). Departamento de Sociologia do ISCTEIUL, Lisboa.

Martins, S. C. (2012). Escolas e estudantes da Europa: Estruturas, recursos e políticas de educação. Lisboa: Mundos Sociais.

Martins, S. C., Mauritti, R., \& Costa, A. F. (2007). Padrões de vida na sociedade contemporânea. In M. D. Guerreiro, A. C. Torres, \& L. Capucha (Orgs.), Quotidiano e qualidade de vida (Portugal no contexto europeu, vol. III) (pp. 263281). Lisboa: Celta Editora.

Martins, S. C., Nunes, N., Mauritti, R., \& Costa, A. F. (2014). O que nos dizem as desigualdades educacionais sobre as outras desigualdades? Uma perspetiva comparada à escala europeia. In B. P. Melo, A. Diogo, M. Ferreira, J. T. Lopes, \& E. E. Gomes (Orgs.), Entre crise e euforia: Práticas e políticas educativas no Brasil e em Portugal (pp. 845-868). Porto: Faculdade de Letras da Universidade do Porto.

Maurin, E. (2009). La peur du déclassement. Une sociologie des récessions. Paris: Le Seuil.

Mauritti, R., \& Martins, S. C. (2014). Consumos de classe média num Portugal em crise: Cultura, lazer e tecnologias de informação. Sociologias, V(37), 144-17.

Meschi, E., \& Scervini, F. (2012). Expansion of schooling and educational inequality in Europe: Educational Kuznets curve revisited. AIAS, GINI Discussion, Paper 61.

Oesch, D. (2015). Welfare regimes and change in the employment structure: Britain, Denmark and Germany since 1990. Journal of European Social Policy, 25(1), 1-17.

Silva, P. A. (2009). Waving the European flag in a Southern European welfare state: Factors behind domestic compliance with European social policy in Portugal. Florence: European University Institute.

Therborn, G. (1995). European modernity and beyond. The trajectory of European societies 1945-2000. Londres: Sage.

van Doorn, M., Pop, I., \& Wolbers, M. H. J. (2011). Intergenerational transmission of education across European countries and cohorts. European Societies, 13(1), 93-117. 
van Werfhorst, H. G. (2007). Scarcity and abundance: Reconciling trends in the effects of education on social class and earnings in Great Britain 1972-2003. European Sociological Review, 23(2), 239-261. 


\title{
IS EDUCATION STILL IMPORTANT TO SOCIAL MOBILITY? A PERSPECTIVE OF EDUCATIONAL INEQUALITIES IN SOUTHERN EUROPE IN THE EUROPEAN CONTEXT
}

\begin{abstract}
With the widespread expansion of educational processes in Europe, some approaches that have been proposed argue that the educational dimension has been weakened as a factor involved in social mobility processes and as a structural element in social opportunities and inequalities. This paper discusses these proposals, contradicting them through alternative theoretical positions and a solid empirical base. The developed analysis envisages educational inequalities and their impacts on social mobility and inequality in targeted manner in Southern Europe and in the European context. This perspective was also sustained by a comparison between countries and recognized over time (last 60 years). Some questions were developed, empirically sustained, particularly concerning the importance of socioeducational backgrounds in the socio-education and socio-occupational destinations and the identification of patterns of social fluidity and educational inequalities, drawing matches with different educational transitions in national terms. We used as central database the European Social Survey (2012).
\end{abstract}

Keywords

Educational inequalities; Social mobility; Southern Europe; European context

\section{¿LA EDUCACIÓN SIGUE SIENDO IMPORTANTE A LA MOVILIDAD SOCIAL? UNA PERSPECTIVA DE LAS DESIGUALDADES EDUCATIVAS EN EL SUR DE EUROPA EN EL CONTEXTO EUROPEO}

\section{Resumen}

Con la expansión generalizada de la educación en Europa, algunos enfoques han sido el argumento de que la dimensión educativa se ha debilitado como 
factor implicado en la movilidad social y como elemento estructural de la desigualdad y las oportunidades sociales. Este artículo discute estos entendimientos, ya sea en sus posiciones teóricas, ya sea en su verificación empírica. Desarrolla el análisis de las desigualdades educativas y su impacto en la movilidad y las desigualdades sociales entre los países del Sur y entre este conjunto y la Europa. Eso se contextualiza aún más por reconocer las dinámicas educativas de los últimos 60 años. El desarrollo de este análisis también apunta a la profundización de la importancia de los antecedentes educativos en los destinos educativos y socio-profesionales e a identificar patrones de fluidez educativa y la desigualdad educativa, contextualizándolos en las transiciones educativas diferenciadas en términos nacionales. La base de la European Social Survey (2012) es la referencia empírica central.

Palabras-clave

Desigualdades educativas; Movilidad social; Sur de Europa; Contexto europeo

Recebido em janeiro/2016

Aceite para publicação em agosto/2016

i Centro de Investigação e Estudos de Sociologia, Instituto Superior de Ciências do Trabalho e da Empresa do Instituto Universitário de Lisboa (ISCTE-IUL).Gulbenkian Professorship. Portugal.

ii Centro de Investigação e Estudos de Sociologia, Instituto Superior de Ciências do Trabalho e da Empresa do Instituto Universitário de Lisboa (ISCTE-IUL), Portugal.

iii Centro de Investigação e Estudos de Sociologia, Instituto Superior de Ciências do Trabalho e da Empresa do Instituto Universitário de Lisboa (ISCTE-IUL), Portugal.

iv Centro de Investigação e Estudos de Sociologia, Instituto Superior de Ciências do Trabalho e da Empresa do Instituto Universitário de Lisboa (ISCTE-IUL), Portugal.

v Instituto Superior de Ciências Sociais e Políticas, Universidade de Lisboa, Portugal.

Toda a correspondência relativa a este artigo deve ser enviada para: Susana da Cruz Martins, ISCTE-IUL, Edifício ISCTE, Av. das Forças Armadas, 1649-026 Lisboa, Portugal. E-mail: susana.martins@iscte.pt 